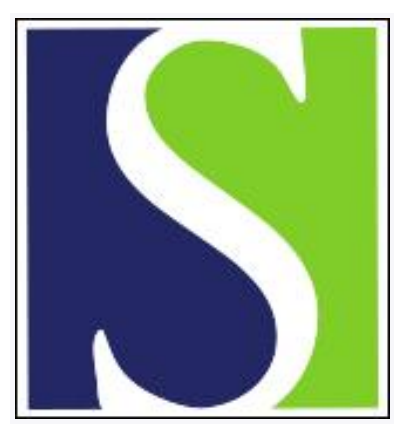

Scand J Work Environ Health 2004;30(4):299-305

https://doi.org/10.5271/sjweh.798

Issue date: Aug 2004

Sleep strategies of 12-hour shift nurses with emphasis on night sleep episodes

by Daurat A, Foret J

Affiliation: Université Toulouse Le Mirail, Laboratoire "Travail et Cognition", UMR CNRS 5551, Maison de la Recherche, 5 allées A Machado, F-31508 Toulouse cedex 9, France. daurat@univ-tlse2.fr

Key terms: 12-hour shift nurse; circadian rhythm; naps during nightshifts; night sleep; nightwork; nurse; sleep; sleep strategy; sleepiness

This article in PubMed: www.ncbi.nlm.nih.gov/pubmed/15458013

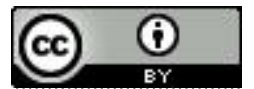




\title{
Sleep strategies of 12-hour shift nurses with emphasis on night sleep episodes
}

\author{
by Agnès Daurat, $P h D,{ }^{1}$ Jean Foret, $P h D^{2}$
}

\begin{abstract}
Daurat A, Foret J. Sleep strategies of 12-hour shift nurses with emphasis on night sleep episodes. Scand J Work Environ Health 2004;30(4):299-305.
\end{abstract}

\begin{abstract}
Objectives Episodes of sleep during a nightshift are frequently reported in various types of jobs. This phenomenon has been seldom documented so far. This field study investigated individual differences in the sleep-wake behavior of nurses.

Methods A group of eight nurses working in an intensive care unit on a two 12-hour shift system kept a "sleep diary" for 1 month, recording main sleep periods and naps. They subjectively assessed sleepiness, sleep quality, and the need for sleep at various times of the day and night. Continuous actimetric measurements provided an evaluation of the rest-activity patterns and of the sleep parameters.

Results Half of the nurses chose to take naps in $75 \%$ of their nightshifts. No differences between the nightnappers and nonnight-nappers were found for either total sleep length or the temporal patterns of subjective sleepiness at night but, during nightwork, night-nappers needed sleep earlier than nonnight-nappers. They had long naps during a worknight and short daytime sleep, sometimes followed by a late afternoon nap. This strategy probably favored the maintenance of a diurnal orientation. Nonnight-nappers had long daytime sleep and took preventive naps to anticipate sleepiness during nightwork. However, their readjustment to diurnal life seemed more difficult than that of night-nappers.

Conclusions Nurses use different sleep-wake strategies to cope with nightwork. These different strategies may be due to circadian influence although social factors cannot be totally excluded.
\end{abstract}

Key terms circadian rhythms, naps during nightshifts, nightwork, sleepiness.

There is a considerable natural interindividual variability in sleeping patterns (morning or evening types, etc) which night work makes even more evident. In some favorable cases, arrangements within a work team during nightwork are possible (ie, a common agreement being reached among its members to take short rest periods if they wish) (1). This is the case for nurses working in many hospital night services. Nurses working night services have been extensively studied for various reasons. They are mainly women (ie, responsible for child care), they work on shifts governed by extremely varied schedule systems, and they frequently take short naps during nightshifts (2).

The benefits and detrimental consequences of night naps have already been examined in studies in which the time and length of sleep were fixed, either in the laboratory (3-5) or in real settings (1, 6-9). In contrast, descriptions of real sleep episodes during nightwork outside any specific experiment and without any formal authorization are scarce (10).

The purpose of this field study was to describe individual differences in the sleep strategy of a group of nurses, with emphasis on sleep episodes during nightwork.

\section{Participants and methods}

\section{Participants}

The study was carried out in an intensive care unit of a public hospital (12 units in all; 650 employees) with the permission of the hospital's director. Eight nurses (seven female, one male) work in this unit. They all volunteered to participate. They were in good health and free of medication and drugs. A questionnaire about

1 Laboratoire “Travail et Cognition”, Université de Toulouse-II (Work and Cognition Laboratory, Tolouse II University), Toulouse, France.

2 Equipe INSERM 0218, Université de Caen ISERM 0218, Caen University, Caen, France.

Reprint requests to: Dr Agnès Daurat, Université Toulouse Le Mirail, Laboratoire “Travail et Cognition”, UMR CNRS 5551, Maison de la Recherche, 5 allées A Machado, F-31058 Toulouse cedex 9, France. [E-mail: daurat@univ-tlse2.fr] 
demographic variables, the number of years in shiftwork, diurnal type (11), and home-work distance was filled out by the nurses (table 1). When the work could be handled by one nurse, the second of the team sometimes chose to take a nap that could be interrupted in case of emergency. Otherwise she (or he) was awakened at the time agreed upon. Therefore, the nurses were divided into two groups, those who slept during workhours (called night-nappers) and those who did not (nonnightnappers). All night naps were noted in a diary by the nurses, and the data were confirmed by actimetry. The shortest nap recorded by actimetry was 25 minutes. The night-nappers and nonnight-nappers did not differ in terms of age, gender, diurnal type, or the number of years in shiftwork. Commuting distances were similar for both groups. Marital status was similar for the two groups. One nurse, in the napper group, lived with an 8 -year-old child.

The nurses worked in 12-hour shifts for 1 month on a dayshift (0800-2000), then for 1 month on a nightshift (2000-0800), and so on. During the nightshift, the weekly work schedule was 1 night's work-1 day off-1 night's work-2 days off-2 nights' work, alternating with 1 day off- 1 night's work-1 day off-2 nights' work-2 days off. The sleep-wake cycles were studied for at least 6 days off during the dayshift period and for 14 consecutive days during the nightshift period. The nurses were encouraged to follow their normal sleeping and napping habits. Since we focused on spontaneous sleep-wake patterns during the nightshift period, daytime work was not included in the analyses.

\section{Methods}

The data used in the analyses were obtained from questionnaires (diaries kept by the nurses) and actimetric recordings.

The participants kept sleep and nap diaries. Each day for 1 month, the nurses reported the time that sleep began and ended, as well as the time of nap onset and ending.

Actimetry was used in conjunction with the sleep diaries to confirm the subjective reports of the length of sleep and nap episodes. Motor activity was recorded continuously with an Actiwatch monitor worn on the nondominant wrist (Cambridge Neurotechnology, Cambridge, UK). Activity counts were stored in 1-minute epochs. Sleep duration was visually identified as the period between the first no-movement epoch after 5 minutes of an immobility span after lights out and the last no-movement epoch preceding continuous activity.

The following measurements were performed (Actisom software ${ }^{\circledR}$ ) and used in the analyses: (i) the activity index, used as an index of sleep quality (index of sleep fragmentation: the higher the activity index, the more fragmented the sleep), was defined as the percentage of active epochs (ie, 1-minute epochs with an activity count $>5$ ) across the resting period and (ii) the mean level of activity was calculated over 24 hours from 2000 (start of the nightwork) to 2000 the following day.

Subjective sleepiness was assessed by the nurses on a visual analogue scale on rising after the main sleep episode (nighttime sleep during days off in both the dayand nightshift periods, daytime sleep after nightwork). The participants were asked to place a mark on a 100 $\mathrm{mm}$-line to indicate their own personal range of feeling at that moment.

Subjective sleep quality was measured when the nurses got up after the main sleep episode (nighttime sleep during days off in both the day- and nightshift periods, daytime sleep after nightwork). The nurses were asked to rate the quality of their sleep using a score from 0 to 4 , as very bad (0), bad, medium, good or very good (4).

The subjective need for sleep was assessed during the workhours. The nurses were asked to note the number of times they needed sleep in a logbook every 2 hours (between 2000 and 2200, 2200 and 2400, 2400 and 0200,0200 and 0400, 0400 and 0600, or 0600 and 0800).

\section{Statistical analyses}

Data obtained during the days off in the dayshift period were used to determine the baseline condition. For each

Table 1. Profiles of the nurses who took naps (night-nappers) or did not (nonnight-nappers) during night work. (SEM = standard error of the mean)

\begin{tabular}{|c|c|c|c|c|c|c|c|c|c|c|c|c|c|}
\hline \multirow[t]{2}{*}{ Group } & \multicolumn{2}{|c|}{ Age (years) } & \multicolumn{2}{|c|}{ Gender } & \multicolumn{2}{|c|}{$\begin{array}{l}\text { Morningness- } \\
\text { eveningness }\end{array}$} & \multicolumn{2}{|c|}{$\begin{array}{l}\text { Years in } \\
\text { shiftwork }\end{array}$} & \multicolumn{3}{|c|}{$\begin{array}{c}\text { Marital status } \\
\text { (number of nurses) }\end{array}$} & \multicolumn{2}{|c|}{$\begin{array}{l}\text { Home-work } \\
\text { distance }(\mathrm{km})\end{array}$} \\
\hline & Mean & SEM & $\begin{array}{l}\text { Male } \\
(\mathrm{N})\end{array}$ & $\begin{array}{l}\text { Female } \\
\text { (N) }\end{array}$ & Mean & SEM & Mean & SEM & $\begin{array}{l}\text { Single } \\
(N)\end{array}$ & $\begin{array}{c}\text { Married } \\
\text { or co- } \\
\text { habitat- } \\
\text { ing a }(N)\end{array}$ & $\begin{array}{l}\text { Single b } \\
\text { (N) }\end{array}$ & Mean & SEM \\
\hline Night-nappers & 29.25 & 3.4 & & 4 & 46.6 & 7.4 & 7.5 & 0.96 & - & 1 & 1 & 4.7 & 2.4 \\
\hline Nonnight-nappers & 35.25 & 3.3 & 1 & 3 & 42.8 & 3.5 & 13 & 4.45 & 3 & 3 & - & 2.5 & 1.9 \\
\hline
\end{tabular}

${ }^{a}$ No children.

${ }^{b}$ One child (8 years of age). 
of the eight nurses, the data covered six nighttime sleep episodes during days off in the dayshift period, six daytime sleep episodes and six nighttime sleep episodes during days off in the nightshift period. A three-way, repeated-measures analysis of variance (ANOVA) was performed using these data with sleep condition (3 levels: nighttime sleep during days off on the day shift, nighttime sleep during days off on the nightshift, daytime sleep), group (night-nappers versus nonnight-nappers) and days (6 levels) as factors. The assumption that the probabilities determined using the F-test were correct was tested with the use of a sphericity test. If the sphericity test was significant, an adjusted F-test was used (Huynh-Feldt procedure) (12). Post-hoc comparisons were made using a matched or unmatched pairs ttest where appropriate. The correlations between the variables were determined using the averaged mean data of each subject in every sleep condition in the Spearman rank test.

Comparisons of the distribution of naps or the subjective need for sleep between nappers and nonnightnappers were carried out with a chi-square test.

\section{Results}

\section{During workhours}

Naps during nightwork. Half of the nurses ("night-nappers" group) took naps during their nightshifts. Naps took place in $75 \%$ of the shifts (number of naps divided by the number of nightshifts). Their distribution during the workhours is presented in figure 1. The number of nighttime naps gradually increased during the night, peaking between 0400 and 0600 . They lasted 150 (SEM $25)$ minutes. When the duration of a night nap was long, the succeeding daytime sleep duration was short and vice versa. The number of subjects was too low to allow any assessment of correlation.
Subjective need for sleep. The nurses were asked if they needed to sleep during their workhours, and, if so, when this need occurred during the night (between 22002400, 2400-0200, 0200-0400, 0400-0600, or 06000800) (figure 1). The distribution of responses reported by the night-nappers and the nonnight-nappers differed significantly $(\mathrm{P}<0.01)$. Among the night-nappers, the need for sleep appeared between 2200 and 2400 and then gradually increased, while, among the nonnightnappers, it occurred later, in the second part of the night, between 0200 and $0400(\mathrm{P}<0.01)$. Between 0400 and 0600, sleepiness peaked in both groups, but was higher for night-nappers than for nonnight-nappers $(\mathrm{P}<0.01)$. Between 0600 and 0800, sleepiness decreased in both groups, but was significantly higher among the nonnight-nappers than among the night-nappers $(\mathrm{P}<0.01)$.

\section{Daytime sleep characteristics}

The significant results of the ANOVA with repeated measures are presented in table 2. For all the variables, sleep condition and the sleep condition by group interaction (except for the index of activity) had a significant effect. Furthermore, group showed a significant effect with respect to sleep duration and the level of sleepiness on rising.

Daytime sleep duration (diary data). As expected, daytime sleep was significantly shorter than nighttime sleep on the days off during both the dayshift $(\mathrm{t}=9.15$, $\mathrm{P}<0.001)$ and nightshift $(\mathrm{t}=8.97, \mathrm{P}<0.001)$ periods (table 3 ), but its length depended on how far the nurses were into their nightshift period in that it gradually diminished between the first and last day sleep [mean first daytime sleep of 335 (SEM 30) minutes versus a mean last daytime sleep of 272 (SEM 31) minutes, $t=3.1$, $\mathrm{P}<0.01]$. When there was only one worknight between two days off, it was particularly short, 244 (SEM 24) minutes (ie, significantly shorter than the first daytime

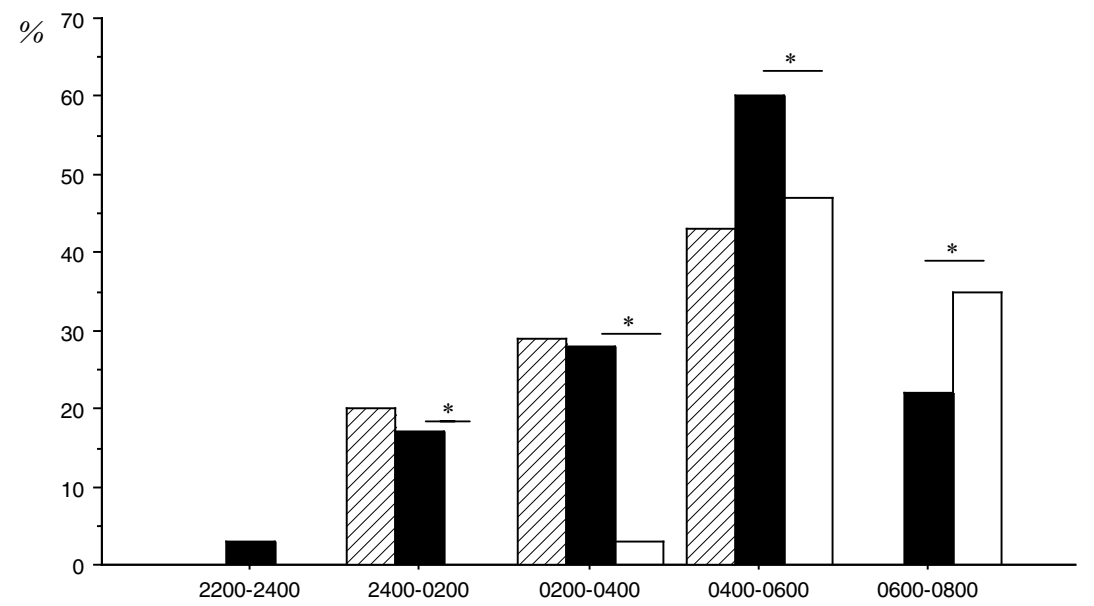

Scand J Work Environ Health 2004, vol 30, no 4
Figure 1. Distribution of the number of naps (per number of worknights) taken by the nightnappers during the worknight (shaded bars). Distribution of times during the worknight when the night-nappers (black bars) and nonnight-nappers (white bars) felt they needed sleep (number of times per 2-hour periods/ number of worknights) ( ${ }^{*} \mathrm{P}<0.01$, significant differences between night-nappers and nonnight-nappers). 
Table 2. Significant results of the analysis of variance with repeated measures - effect of sleep condition, day, group, and sleep condition by group interaction.

\begin{tabular}{llccc}
\hline Effect & $\begin{array}{c}\text { Degrees of } \\
\text { freedom }\end{array}$ & $\begin{array}{c}\text { F- } \\
\text { value }\end{array}$ & $\begin{array}{c}\text { P- } \\
\text { value }\end{array}$ & $\begin{array}{c}\text { Huynth-Feldt } \\
\text { epsilon }\end{array}$ \\
\hline Sleep duration & & & & \\
$\quad$ Sleep condition & $1.99,9.53$ & 121 & 0.0001 & 0.8 \\
$\quad$ Day & 5,30 & 2.6 & 0.05 & 1 \\
$\quad$ Group & 1,6 & 5.8 & 0.05 & \\
$\quad$ Condition x group & $1.6,9.53$ & 4.8 & 0.05 & \\
Index of activity & & & & \\
$\quad$ Sleep condition & $1.55,9.3$ & 5 & 0.05 & 0.78 \\
Sleep quality & & & & \\
$\quad$ Sleep condition & 2,12 & 4.6 & 0.05 & 1 \\
$\quad$ Condition x group & 2,12 & 4.7 & 0.05 & \\
Sleepiness on rising & & & & \\
$\quad$ Sleep condition & 2,12 & 4.75 & 0.05 & 1 \\
$\quad$ Group & 1,6 & 6.15 & 0.05 & \\
$\quad$ Condition x group & 2,12 & 6.8 & 0.01 & \\
Mean level of activity & (rest-activity rhythm) & & \\
$\quad$ Sleep condition & 2,12 & 9 & 0.01 & 1 \\
Condition x group & 2,12 & 9.5 & 0.01 & \\
\hline
\end{tabular}

Table 3. Sleep duration during the daytime after a worknight and days off in both the day- and nightshift periods (diary reports).

\begin{tabular}{|c|c|c|c|c|c|c|}
\hline \multirow[t]{2}{*}{ Group } & \multicolumn{2}{|c|}{$\begin{array}{l}\text { Daytime } \\
\text { sleep } \\
\text { (minutes) }\end{array}$} & \multicolumn{2}{|c|}{$\begin{array}{l}\text { Days off on } \\
\text { dayshift } \\
\text { (minutes) }\end{array}$} & \multicolumn{2}{|c|}{$\begin{array}{l}\text { Days off on } \\
\text { nightshift } \\
\text { (minutes) }\end{array}$} \\
\hline & Mean & SEM & Mean & SEM & Mean & SEM \\
\hline Night-nappers & $194^{\mathrm{a}}$ & 20 & $525^{b}$ & 24 & $504^{b}$ & 32 \\
\hline Nonnight-nappers & 359 & 22 & $545^{b}$ & 26 & $530^{b}$ & 32 \\
\hline All nurses & 286 & 18 & $534^{b}$ & 20 & $516^{b}$ & 23 \\
\hline
\end{tabular}

a $\mathrm{P}<0.05$, significant differences between night-nappers and nonnightnappers.

b $\mathrm{P}<0.001$, significant differences from daytime sleep duration.

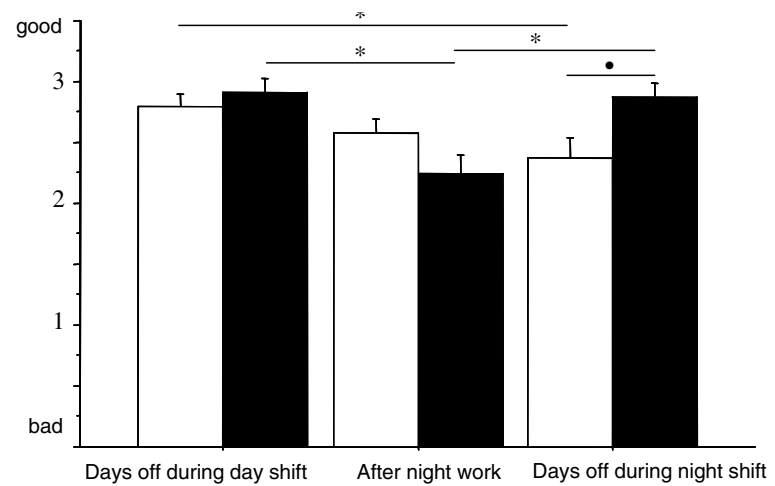

Figure 2. Subjective quality of sleep (means and standard errors of the means) during days off in both the dayshift and nightshift periods and of daytime sleep (after a worknight) for the night-nappers (black bars) and nonnight-nappers (white bars) $\left({ }^{*} P<0.05\right)$.

sleep in a row of several nights of work) $(\mathrm{t}=4.7, \mathrm{P}<0.01)$, and equivalent to a last daytime sleep. This reduction was linked to an earlier rising time [1326 (SEM 40 minutes) versus 1447 (SEM 37 minutes), $\mathrm{t}=4.1, \mathrm{P}<0.01]$.
No difference in the length of the nighttime sleep was found between the nightshift and dayshift periods. During days off on a dayshift, the duration of sleep on the last day off (just before the first nightshift) was significantly longer by 45 (SEM 23) minutes than the mean duration of the other days off $(\mathrm{t}=2.5, \mathrm{P}<0.05)$.

Effect of group. The daytime sleep of the night-nappers was significantly shorter than that of nonnight-nappers [194 (SEM 20) minutes versus 359 (SEM 22) minutes, $\mathrm{t}=3.12, \mathrm{P}<0.05]$. This difference can be explained by the significant delay in bedtime $[1015$ ( \pm 45 minutes $)$ versus 0900 ( \pm 20 minutes), $\mathrm{t}=-2.4, \mathrm{P}<0.05]$. The daytime sleep of the habitual nappers was as short with a night nap as it was without a night nap [194 (SEM 20) minutes versus 216 (SEM 20) minutes], but the number of worknights without naps was too low to allow any significant comparison to be made. The total sleeptime (ie, nighttime nap plus daytime sleep) did not significantly differ from the length of the main daytime sleep of nonnappers [311 (SEM 18) minutes versus 359 (SEM 22) min, $\mathrm{t}=0.2$, not significant $]$.

The sleep duration during the days off did not differ between the groups (table 3 ).

Actimetry data. The activity index was higher for the nighttime sleep on the days off in both the day- and nightshift periods (ie, the nighttime sleep was more fragmented than the daytime sleep) $(\mathrm{t}=2.7, \mathrm{P}<0.05$, and $\mathrm{t}=3.7, \mathrm{P}<0.01$, respectively). The night-nappers had a lower activity index for night naps than for the nighttime sleep on days off (dayshift: $\mathrm{t}=2.9, \mathrm{P}<0.05$; nightshift: $\mathrm{t}=3.9, \mathrm{P}<0.05$ ), but the values did not differ significantly from those of daytime sleep.

Subjective sleep quality. The quality of daytime sleep was worse than that of nighttime sleep on the days off on the dayshift $(\mathrm{t}=2.54, \mathrm{P}<0.05)$. During the days off while on a nightshift, the quality of night sleep was better than that of day sleep, but the difference did not reach significance $(\mathrm{t}=1.8, \mathrm{P}<0.12)$.

Effect of group. Among the night-nappers, the quality of daytime sleep was worse than that of nighttime sleep on days off during both the day- and nightshift periods $(\mathrm{t}=3.1, \mathrm{P}<0.05)$. For the nonnight-nappers, the quality of sleep on days off during a nightshift was worse than that of the dayshift $(\mathrm{t}=2.9, \mathrm{P}<0.05)$ and also worse than that of the night-nappers $(\mathrm{t}=2.326 \mathrm{P}<0.05)$ (figure 2$)$.

Daytime sleep quality correlated with the length of sleep only for the night-nappers (night-nappers: $r h o=0.91$, $\mathrm{P}<0.01$; nonnight-nappers: rho $=0.23$, not significant).

Sleepiness on rising. The sleepiness level on rising was significantly higher after daytime sleep than after 
nighttime sleep on days off during the day shift ( $\mathrm{t}=2.8$, $\mathrm{P}<0.05$ ), with the same trend being observed for days off during the nightshift $(\mathrm{t}=1.93, \mathrm{P}<0.1)$.

Effect of group. On rising after daytime sleep, the sleepiness level of night-nappers was significantly higher than that of the nonnight-nappers $(\mathrm{t}=3.6, \mathrm{P}<0.01)$. It was also higher than after nighttime sleep on days off during both the dayshift $(\mathrm{t}=3.14, \mathrm{P}<0.05)$ and nightshift $(\mathrm{t}=5.5, \mathrm{P}<0.01)$ periods. It correlated with the length of sleep $($ rho $=-0.56, \mathrm{P}<0.05)$ (figure 3 ).

Among the nonnight-nappers, the sleepiness level did not significantly vary across the different sleep conditions, and it did not correlate with the sleep duration or the activity index.

\section{Daytime naps}

Naps were observed on two occasions in the afternoon of a day off just before a night of work [called "preventive naps", which can be related to the "prophylactic naps" discussed by Bonnet \& Arand (13)] and in the late afternoon in order to complement insufficient morning sleep (called "recuperative naps"). All the naps were reported by the nurses in the diary and were confirmed by actimetry. Only one nap was short (15 minutes), the length of the others being greater than $30 \mathrm{~min}-$ utes.

Preventive naps were observed in $41 \%$ of the shifts (number of naps divided by the number of nightshifts). They occurred at 1455 (SEM 54 minutes) and lasted 88 (SEM 12) minutes. Their duration correlated negatively with the length of the preceding main nighttime sleep (rho=-0.68, $\mathrm{P}<0.01$ ).

Recuperative naps were taken in $28 \%$ of the shifts (number of recuperative naps divided by the number of worknights). They occurred at 1726 (SEM 36 minutes) and lasted 66 (SEM 8) minutes. Their length tended to be negatively correlated with the length of the preceding daytime sleep (rho $=-0.34, \mathrm{P}<0.1)$.

Effect of group. The frequency of preventive naps was greater for the nonnight-nappers than for the night-nappers $(48 \%$ of the shifts of the nonnight-nappers versus $33 \%$ of the shifts of the night-nappers, $\mathrm{P}<0.01$ ), while the reverse was found for recuperative naps $(33 \%$ versus $22 \%, \mathrm{P}<0.01)$.

\section{Mean level of activity}

As expected, the mean level of activity (calculated over 24 hours from 2000 to 2000) of the days off during a nightshift was significantly lower than when on duty $(\mathrm{t}=2.5, \mathrm{P}<0.05)$ (table 4$)$. It was also lower than during the days off on a dayshift $(\mathrm{t}=3.06, \mathrm{P}<0.05)$.
Effect of group. For the nonnight-nappers, the mean level of activity strongly diminished during the days off on a nightshift and became significantly lower than when on duty $(\mathrm{t}=3.4, \mathrm{P}<0.05)$.

In contrast, night-nappers had a level of activity that was lower when on duty than during days off on a dayshift $(t=6.7, P<0.01)$. During the days off on a nightshift, it was also lower than during the days off on a dayshift $(\mathrm{t}=5.7, \mathrm{P}<0.01)$, but it tended to increase relative to when on duty. Therefore, when the nurses were working, their mean level of activity was lower than that of the nonnight-nappers $(\mathrm{t}=3.6, \mathrm{P}<0.01)$.

\section{Discussion}

Our study of spontaneous sleep-wake behavior confirms that sleep length is strongly reduced during nightwork

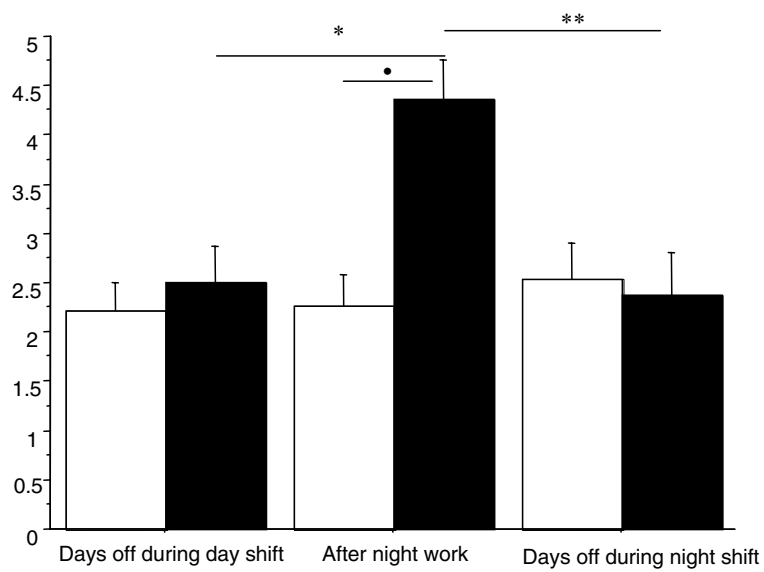

Figure 3. Subjective sleepiness (scale $0-10$; means and standard errors of the means) of the night-nappers (black bars) and nonnightnappers (white bars) on rising after nighttime sleep during days off in both the day- and nightshift periods and after daytime sleep $\left({ }^{*} P<0.05\right.$; $\left.{ }^{*} \mathrm{P}<0.01 ; \cdot \mathrm{P}<0.01\right)$.

Table 4. Mean level of activity calculated over 24 hours from 2000 (start of the nightwork) to 2000 of the following day (movements/ minute).

\begin{tabular}{|c|c|c|c|c|c|}
\hline \multirow[t]{3}{*}{ Group } & \multicolumn{5}{|c|}{ Level of activity } \\
\hline & \multicolumn{2}{|c|}{$\begin{array}{l}\text { Days off on } \\
\text { dayshift }\end{array}$} & \multicolumn{2}{|c|}{$\begin{array}{l}\text { When on } \\
\text { duty }\end{array}$} & $\begin{array}{c}\text { Days off on } \\
\text { nightshift }\end{array}$ \\
\hline & Mean & SEM & Mean & SEM & Mean SEM \\
\hline Night-nappers & 243 & 18 & $184^{a}$ & 14 & $196^{a} \quad 12$ \\
\hline Nonnight-nappers & 210 & 20 & $230^{b}$ & 13 & $166^{c} \quad 12$ \\
\hline All nurses & 223 & 15 & 212 & 11 & $179 c, d$ \\
\hline \multicolumn{6}{|c|}{$\begin{array}{l}\text { a } P<0.01 \text {, significant differences from days off in dayshift period. } \\
\text { b } P<0.01 \text {, significant differences between night-nappers and nonnight- } \\
\text { nappers. } \\
\text { c } P<0.05 \text {, significant differences from when the nurses were on duty. } \\
\text { d } P<0.05 \text {. }\end{array}$} \\
\hline
\end{tabular}


$(7,10)$ when compared with the situation on days off, the result being a widespread napping behavior during daywork and during nightwork (14). There was considerable variability among the nurses, who could be divided into two groups, one which slept during their workhours and had short daytime sleep and one which did not sleep during work but took preventive naps before work and had long daytime sleep.

The activity index of daytime sleep (fragmentation index) was lower than that of nighttime sleep on the days off and indicated deeper sleep; this finding was in good agreement with that of other studies $(10,15)$, which demonstrated that, in daytime sleep, awake time and stage 2 and rapid eye movement sleep were strongly reduced, while slow-wave sleep was unaffected. As expected, daytime sleep had a shorter duration than nighttime sleep on the days off, but its length depended on its position in the schedule. When there were several nights in a row, the length of the daytime sleep was shorter after the last night of work than after the first night; this finding confirmed the results of previous studies $(7,16)$. This observation cannot be explained by an increasingly disturbed sleep during worknights because, when there was one worknight between two days off, the daytime sleep was shorter than the first daytime sleep in a row of several worknights. Instead, reducing morning sleep would appear to be a deliberate strategy for increasing sleep pressure the following night and for returning more rapidly to diurnal life.

During workhours, the need for sleep showed the well-known circadian pattern, peaking between 0400 and 0600 , in accordance with the findings of all the previous studies (17). Preventive naps (early afternoon) were observed in $41 \%$ of the cases, especially when the preceding night's sleep had been short. In the same way, the duration of sleep on the last day off in the dayshift period (just before the first nightshift) was significantly greater than that of the other days off during the day shift. The nurses probably used both strategies to prevent anticipated fatigue and sleepiness during their first nightshift, which is associated with extended wakefulness (14). Recuperative naps (late afternoon naps after daytime sleep) were observed for $28 \%$ of the shifts. More surprisingly, half of the nurses chose to sleep during nightwork on $75 \%$ of the shifts. They were particularly long (average of 150 minutes). Compared with nurses who did not sleep, night-nappers had significantly less daytime sleep. However, their total sleeptime (nighttime nap plus daytime sleep) did not significantly differ from the length of the nonnappers' daytime sleep. Besides, the duration of their nighttime sleep on days off did not differ from that of nonnappers, and they did not particularly complain of sleepiness or of poor sleep quality. This finding excludes the hypothesis of a stronger sleep requirement among nappers. Thus, for some nurses, the night nap appears to be an essential part of their daily sleep ration, the latter being split into two episodes, a long nap during workhours and a short daytime sleep. Moreover, when their daytime sleep was particularly short, a third episode of sleep took place in the late afternoon (recuperative nap) while, nonnappers took recuperative naps far more seldom.

It is worth noting that sleepiness occurred earlier among the nappers than among the nonnappers and that the low level of the activity index of the night naps suggests that they contained deep sleep; this finding supports the results of findings of Torsvall et al (10). Therefore, the explanation for night naps should be looked for in a more fundamental circadian effect. In this shift design, nightshifts were long (12 hours) and finished late (0800). The shift length per se increased the risk of severe sleepiness (18) and forced nurses to start their morning sleep at an unfavorable time on the ascending limb of the circadian temperature curve (19). Thus a phase difference among individuals could explain the fact that, even when they did not take a nap during workhours (due to a high workload), the subsequent daytime sleep of nappers was shorter than that of nonnappers. Whatever the length of their daytime sleep, the sleepiness they complained of on waking rapidly returned to normal during their days off. Thus, although the length of the night nap influenced the length of the subsequent daytime sleep $(7,8,20)$, the shorter sleep of night-nappers was probably linked more to circadian influence than to homeostatic influence. Quera-Salva et al (21) and Dumont et al (22) showed that a rapid adjustment of the melatonin rhythm is associated with better daytime sleep, shorter naps during workhours and better performance. In our study, the night-nappers had a later sleep in the morning than the nonnappers did. Thus they were probably more exposed to bright light in the morning before going to bed, which may have impeded their circadian adjustment to nightwork, as suggested by Dumont et al (22). Moreover, night naps may act as "anchor" sleep (23) and thus prevent any phase shift in the rest-activity rhythm.

Another possibility is that nappers used significant night naps to help keep a diurnal orientation because it could be an advantageous strategy on a rapid rotation schedule to avoid difficulty in returning to diurnal life. In fact, they did not complain of any more sleepiness or poor sleep quality. Their mean level of activity, very low when on duty, returned to the baseline level, although it remained lower than during the dayshift period. In contrast, when they returned to diurnal life on days off, nonnight-nappers complained of poor sleep quality. Their level of activity was strongly reduced compared with that on nightwork. Thus the apparent ease of nonnappers to keep awake during a nightshift seems to be paid for by difficulties in readjusting to diurnal life. On 
the other hand, although the night- and nonnight-nappers were not differentiated by individual, family, or social factors, we cannot totally exclude the possibility that, as suggested by Matsumoto \& Harada (7), "the night nap could allow part of the essential sleep to be taken in advance of day sleep, thereby creating time for worker's family and social life [p 905]".

In conclusion, this study shows that nurses used different sleep-wake strategies to cope with nightwork. Some adopted a polyphasic sleep pattern, with a long nap during the worknight (anchor sleep) and short daytime sleep, sometimes followed by a late afternoon nap. This strategy probably favored the maintenance of a diurnal orientation and the return to diurnal life. Other nurses, who did not sleep during nightwork, had long daytime sleep and took preventive naps to anticipate sleepiness during nightwork. However, their readjustment to diurnal life seemed to be more difficult. These different strategies seem to be determined by circadian influences. However, our conclusions must be viewed with caution, as the sample was small and specific (relatively young women without any family responsibilities). Other, possibly more subtle, social factors cannot be excluded. Additional studies with more participants and interviews of shift workers are needed.

\section{References}

1. Bonnefond A, Muzet A, Winter-Dill AS, Bailloeuil C, Bitouze F, Bonneau A. Innovative working schedule: introducing one short nap during the night shift. Ergonomics 2001;44:937-45.

2. Barthe B. Gestion collective de l'activité de travail et variation de la vigilance: le cas des équipes hospitalières en postes de nuit longs [Cooperative management of work activity and night alertness variations: the case of hospital teams in extended night shifts] [dissertation]. Toulouse (France): Université Toulouse II; 1999.

3. Sallinen M, Härmä M, Akerstedt T, Rosa R, Lillqvist O. Promoting alertness with a short nap during a night shift. J Sleep Res 1998;7:240-7.

4. Gillberg M. The effects of two alternative timings of a onehour nap on early morning performance. Biol Psychol 1984;19:45-54.

5. Matsumoto K. Effects of nighttime naps on body temperature changes, sleep patterns and self-evaluation of sleep. J Human Ergol 1981;10:173-84.

6. Matsumoto K, Morita Y. Effects of nighttime nap and age on sleep patterns of shift workers. Sleep 1987;10:580-9.
7. Matsumoto K, Harada M. The effect of night-time naps on recovery from fatigue following night work. Ergonomics 1994;37:899-907.

8. Rosekind MR, Smith RM, Miller DL, Co EL, Gregory KB, Webbon LL, et al. Alertness management: strategic naps in operational settings. J Sleep Res 1995;4 Suppl 2:62-6.

9. Purnell MT, Feyer AM, Herbison GP. The impact of a nap opportunity during the night shift on the performance and alertness of 12-h shift workers. J Sleep Res 2002;11:219-27.

10. Torsvall L, Akerstedt, Gillander K, Knutsson A. Sleep on the night shift: 24-hour monitoring of spontaneous sleep/wake behaviour. Psychophysiology 1989;26:352-8.

11. Horne JA, Östberg O. A self-assessment questionnaire to determine morningness-eveningness in human circadian rhythms. Int J Chronobiol 1976;4:97-110.

12. Huynh H, Feldt LS. Estimation of the Box correction for degrees of freedom from data in the randomized block and split plot designs. J Educ Stat 1976; 1:69-82.

13. Bonnet MH, Arand DL: The use of prophylactic naps and caffeine to maintain performance during a continuous operation. Ergonomics 1994;37:1009-20.

14. Akerstedt T, Torsvall L, Gillberg M. Shift work and napping. In: Dinges DF, Broughton RJ, editors. Sleep and alertness: chronobiological, behavioral and medical aspects of napping. New York (NY): Raven Press, Ltd; 1989. p 205-20.

15. Akerstedt T, Gillberg M. Subjective and objective sleepiness in the active individual. Int J Neurosci 1990;52:29-37.

16. Novak RD, Auvil-Novak SE. Focus group evaluation of night nurse shiftwork difficulties and coping strategies. Chronobiol Int 1996;13:457-63.

17. Akerstedt T, Torsvall L, Gillberg M. Sleepiness and shift work. Sleep 1982;Suppl 2:S95-S106.

18. Härmä M, Sallinen M, Ranta R, Mutanen P, Müller K. The effect of an irregular shift system on sleepiness at work in train drivers and railway traffic controllers. J Sleep Res 2002;11:141-51.

19. Czeisler CA, Weitzman ED, Moore-Ede MC, Zimmerman JC, Knauer RS. Human sleep: its duration and organization depend on its circadian phase. Science 1980;210:1264-7.

20. Sakai K, Watanabe A, Onishi T, Shindo H, Kimotsuki K, Saito $\mathrm{H}$, et al. Conditions of night naps effective to facilitate recovery from night work fatigue. J Sci Labour 1984;60:45178 .

21. Quera-Salva MA, Guilleminault C, Claustrat B, Defrance R, Gajdos P, McCann CC, et al. Rapid shift in peak melatonin secretion associated with improved performance in short shift work schedule. Sleep 1997;20:1145-50.

22. Dumont M, Benhaberou-Brun D, Paquet J. Light exposure and circadian phase of melatonin secretion in night workers. J Biol Rhythms 2001;16:502-11.

23. Minors DS, Waterhouse JM. Anchor sleep entrain circadian rhythms? evidence from constant routine studies. J Physiol 1983;345:451-67.

Received for publication: 15 August 2003 